\title{
Article \\ The Results of Laboratory Studies of the Device for Evaluation of Suitability of Potato Tubers for Mechanized Harvesting
}

\author{
Alexey Dorokhov, Andrey Ponomarev, Vitaly Zernov, Sergei Petukhov, Alexander Aksenov, Alexey Sibirev * \\ Nikolay Sazonov (D) and Maria Godyaeva
}

check for

updates

Citation: Dorokhov, A.; Ponomarev,

A.; Zernov, V.; Petukhov, S.; Aksenov,

A.; Sibirev, A.; Sazonov, N.;

Godyaeva, M. The Results of

Laboratory Studies of the Device for

Evaluation of Suitability of Potato

Tubers for Mechanized Harvesting

Appl. Sci. 2022, 12, 2171. https://

doi.org/10.3390/app12042171

Academic Editor: Manuel Armada

Received: 6 January 2022

Accepted: 16 February 2022

Published: 19 February 2022

Publisher's Note: MDPI stays neutral with regard to jurisdictional claims in published maps and institutional affiliations.

Copyright: (C) 2022 by the authors. Licensee MDPI, Basel, Switzerland. This article is an open access article distributed under the terms and conditions of the Creative Commons Attribution (CC BY) license (https:// creativecommons.org/licenses/by/ $4.0 /)$.
FSBSI “Federal Scientific Agronomic and Engineering Center VIM", 109428 Moscow, Russia; dorokhov.vim@yadex.ru (A.D.); agrodisel@mail.ru (A.P.); ppovim@mail.ru (V.Z.); petuxov61@bk.ru (S.P.); 1053vim@mail.ru (A.A.); sazonov_nikolay@mail.ru (N.S.); one.and.only@marie-winter.ru (M.G.)

* Correspondence: sibirev2011@yandex.ru; Tel.: +7-89645843518

\begin{abstract}
The purpose of this study is to substantiate the concept of a device for the evaluation of the suitability of varieties and hybrids of potato tubers for mechanical harvesting from the earliest stages of the selection process and to perform quantitative and structural assessment of damage to potato varieties and hybrids inflicted by the device, simulating the process of the harvester's separating element operation depending on the machine type and harvesting conditions. The structural and operating diagram of the device for the evaluation of suitability of varieties and hybrids for mechanized harvesting has been developed, and the procedure and results of the study to determine the force action of the separating surface of the developed device on the potato tubers are presented. The device developed in accordance with the proposed conceptual scheme, further calibrated to account for modern potato harvesters would make it possible to conduct targeted selection of varieties suitable for mechanized cultivation, as well as to assess the degree of resistance of potato varieties to mechanized harvesting at early stages of selective and seed production works.
\end{abstract}

Keywords: potatoes; damage; force; damage simulator; seed production

\section{Introduction}

Existing machines for harvesting potatoes cause damage to marketable products as a result of the interaction of potato tubers with each other, with working bodies and with soil lumps in view of the wide variety of soil and climatic conditions in which the harvesting process takes place. In addition, in uniform soil and climatic conditions within the same accounting plot, there is a large deviation from the average values of the basic physical constants of the soil-moisture and hardness. However, the greatest percentage of damage to potato tubers occurs as a result of their interaction with the working bodies of the harvester. In order to determine the place of the greatest force impact of individual working bodies of machines for harvesting potatoes and to carry out subsequent measures to eliminate these negative effects in the design of harvesting machines, experimental studies were carried out. One of the most important indicators of the quality of machine technology for cultivating and harvesting root crops and potatoes that determines the duration of the storage of root crops is the presence of the deposited pile of soil and plant matter [1,2].

The achievement of the specified agrotechnical requirements is ensured under the maximum permissible strict operating modes of lump-destroying and sifting separating devices of machines for harvesting root crops and onions in order to destroy impassable soil lumps, which leads to increased damage and losses of the separated products.

The impossibility of separating soil lumps from a pile of root crops and onions is due to the fact that slot-separating working bodies are used in most harvesting machines, while the inter-rod distance of the separating conveyor, in order to exclude losses of root crops, is less than the minimum size of the separated root crop, which leads to the impossibility of 
cleaning them on the separating working bodies of harvesting machines and consequently to the injury of a significant part of the marketable products and losses during the storage of a significant part of the grown crop. The lack of methods or their insufficient effectiveness in solving the problem of separating soil lumps from commercial products of root crops and onions in the separating working bodies of harvesting machines, both in the first and in the second phases of harvesting, leads to the widespread use of manual labor in post-harvest refinement operations, which increases the cost of production.

As a result of the analysis of technologies and technical means of machine harvesting of root crops and onions, the main methods and means that contribute to reducing the number of soil lumps in commercial products of root crops and onions during their machine harvesting, which have their positive sides and disadvantages, have been identified. The quality indicators of cleaning are determined by how well the previous technological operations are performed.

The revealed disadvantages of the known methods and technical means of reducing the content of soil impurities in commercial products of root crops and potatoes do not give grounds to exclude them from the practice of research work and consider them a passed stage.

However, it should be concluded that modern technologies and technical means of harvesting root crops and potatoes are not able to ensure the production of high-quality marketable products with minimal labor costs, due to the lag or absence in the development of technological foundations, technologies and working bodies for harvesting root crops and potatoes, as well as a method for monitoring the operational and technological performance of both the harvesting machine as a whole and its working bodies, which have a decisive influence on the qualitative properties of root crops and potatoes. In this regard, it is necessary to ensure the breeding of varieties and hybrids of root crops and potatoes that are resistant to mechanical damage from interactions with functioning elements of the harvesting machine.

A lot of work has been done on potato damage. Parke [1] investigated the effect of impact force upon potato tubers. McGechan [2] investigated the damage susceptibility of different potato varieties. Other authors have considered potato bruising [3-6].

Arc-shaped damage on the surface of a potato is very common, as is skinning, puncturing, and split-arc bruising. A large amount of arc-shaped damage is observed in potatoes during each process following the harvest. Therefore, arc-shaped damage may considerably reduce the sellable price of the potatoes on the market. In this article, the damage caused by impact during harvesting and handling operations prior to shipping have been investigated. Several useful results were obtained for improving machine components and processing plants in order to reduce potato damage.

For the simulation of mechanical loading conditions, the RIAE Prague has developed a device simulating the motion and impact stress of the potato tubers measured (Figure 1) with parameters similar to the system utilized at ATB Bornim [7].

Furthermore, a device for the picture scanning of sample cuttings and their digitalization was manufactured. The samples were evaluated according to the computer program KABI developed for the picture analysis of potatoes.

Therefore, the development and research of technologies and technical means for assessing root crops and potatoes for resistance to mechanical damage during harvesting represents a scientific problem, the solution of which will contribute to the innovative development of the domestic market of agricultural products, the stable position of Russia in the foreign market, and will ensure the transition to highly productive production of agricultural products. As a result, the following will occur:

- $\quad$ An increase in labor productivity;

- Improvement in the quality of products;

- $\quad$ Reducing the cost of production and providing the population of the Russian Federation with valuable food products. 


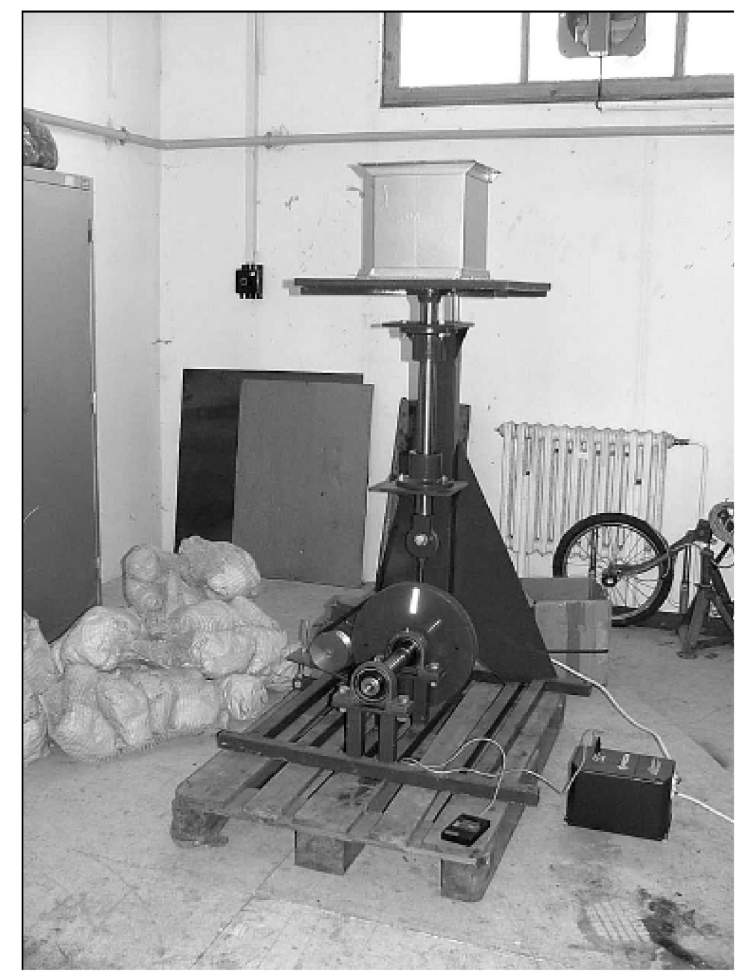

Figure 1. Testing stand of RIAE Prague for samples mechanical loading examination (mechanical loading motion simulator).

At the moment, a machine for harvesting potatoes and root crops has already been invented [6], for which the design of the functioning elements are the basic schemes of modern harvesting machines, with a separation device from soil and plant impurities made in the form of a rod elevator (Figure 1), which is installed at an angle of 10 degrees to the horizon to achieve vertical lifting of the separated products to a height of $0.26 \mathrm{~m}$ to improve cleaning.

The working speed of the web of the bar elevator is $2.5 \mathrm{~m} / \mathrm{s}$, which leads, when interacting with various types of shakers, to a forceful effect on the processed pile of root crops to potatoes and therefore to damage to the products.

Thus, the assessment of the resistance of tubers to mechanical damage during harvesting using industrial harvesting machines cannot be used directly at the initial stages of breeding new varieties. This is only possible at the last stage of the breeding process-before the transfer of the variety to state tests.

In light of consistent introduction of mechanization technologies of cultivation, harvesting and after-harvest processing of potato, and due to the period of tuber storage before their sale or planting, additional demands are placed on the inheritable properties (inheritable traits) of potato plants. The steadily increasing amount of mechanical action on tubers during cultivation, harvesting and placement in storage define the need for the selection of potato varieties for increased resistance to mechanical stress. Mechanical damage is traditionally classified as external (surface) and internal damage. External damage includes types of damage that may be detected by visual inspection: jacket scarring, scratches, cracks, dents, tears, cuts, crushed tubers, etc. Internal damage types include darkening of flesh and internal cracks Lobachevsky, P. A. Emelyanov, A. G. [7-9].

Currently, the intrinsic resistance of tubers to mechanical damage is assessed during regular harvesting with conventional harvesting machines [10-13].

This technique, however, cannot be used at early breeding stages of a new variety; it is applicable to the final stage of the selective process only—before a variety is submitted for state tests [14-17]. 
The results and conclusions of analytical studies of potato tuber damage by the work elements of KKU-2 type harvesters make it possible to specify and adjust the design of modern potato harvesters using experimental studies of potato tuber damageability.

The Research Institute of Potato Breeding (Korenevo Settlement, Luybertsy District, Moscow Region) conducted the most comprehensive, theoretically substantiated and accurate studies of potato tuber damage at specific working elements of KKU-2 Druzhba harvester in cooperation with GSP KTV (Ryazan). The studies were conducted in the Ryazan and the Moscow Regions. During the numerous experiments, tuber damage was determined by sequentially taking samples during harvester stops at each work element. The amount and structure of tuber damage were determined both at the input of each work element and after the tubers left it. Tubers were selected in small batches of 10 pieces at every stop. No adjustments of the harvester have been made during the studies (sampling) [17]

The analysis of the KKU-2 harvester study results [17] made it possible to present the share of work elements and drops in tuber damage as a pie chart (Figure 2).

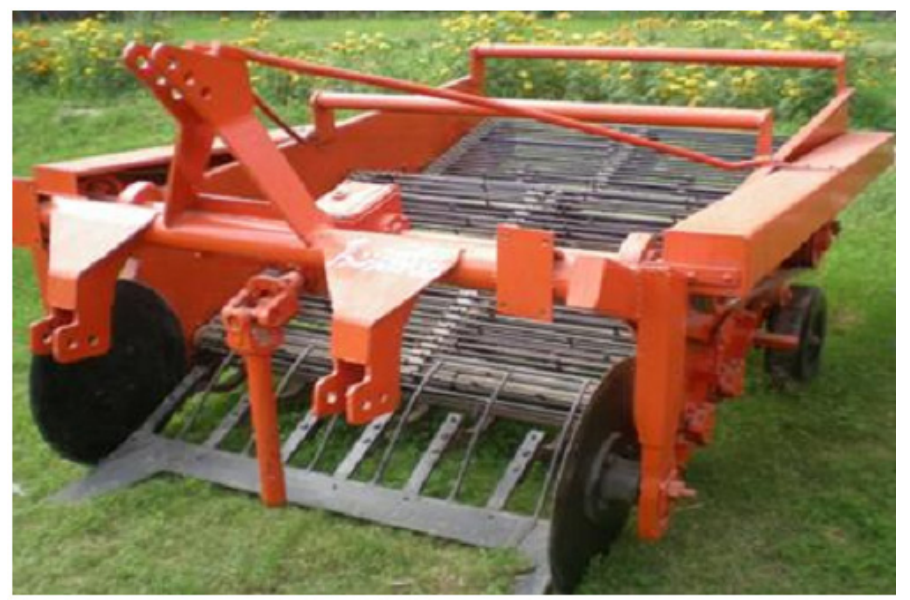

Figure 2. General view of the harvesting root crops machine.

The figure shows that separating work elements account for $63.2 \%$ of damage instances out of the total number of potato tuber damage.

Figure 2 shows the structure (by damage type) of potato tuber damage during collection by a harvester. The diagram (Figure 3 ) shows that internal damages (darkening of flesh) occurring under shock stress by the separating work elements, and drops account for $69.4 \%$ of the total number of damages.

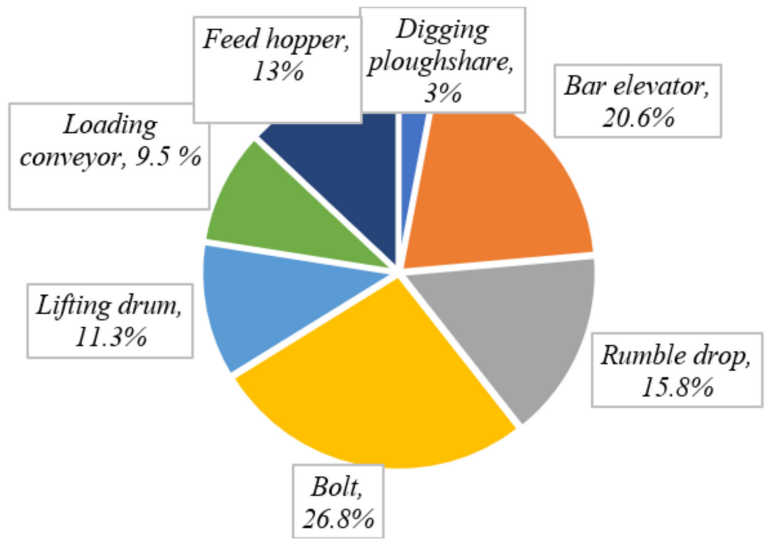

Figure 3. The share of work elements in the damage of potato tubers (percentage of the total damage number by weight). 
To make the presentation of potato tuber damageability at work elements and drops of potato harvesters more intuitive, Figure 4 shows the number of damaged tubers as a stepped diagram.



$52.9 \%$
-Peeling off the peel $1 / 4$ do $1 / 2$ tuber surfaces $4,3 \%$

-Peeling the peel more $1 / 2$ tuber surfaces $-4,1 \%$

DDamage to the pulp with a depth of more than $5 \mathrm{~mm}$ $6,3 \%$

-Cracks longer than $20 \mathrm{~mm}$ $13,3 \%$

\section{UIIIA darkening of tuber flesh (69.4\%)}

Figure 4. The structure of tuber damage during harvester potato pickup as percentage of the total number of damages.

The X-axis of the diagram represents the location of harvester work elements within the sequence of the potato heap travel along them, while the Y-axis represents the number of damages as percentage at a certain work element of the harvester, as a running total. Under the X-axis, the harvester's work elements are shown schematically to conveniently appraise the degree of influence of a specific work element on potato damage, especially during the transition of the heap from one work element to another.

Based on the analysis of the stepped diagram (Figure 5), the pie diagram in Figure 6 was constructed. The diagram shows the relative share of drops and separating work elements in the total amount of potato tuber damage during harvester-based pickup.

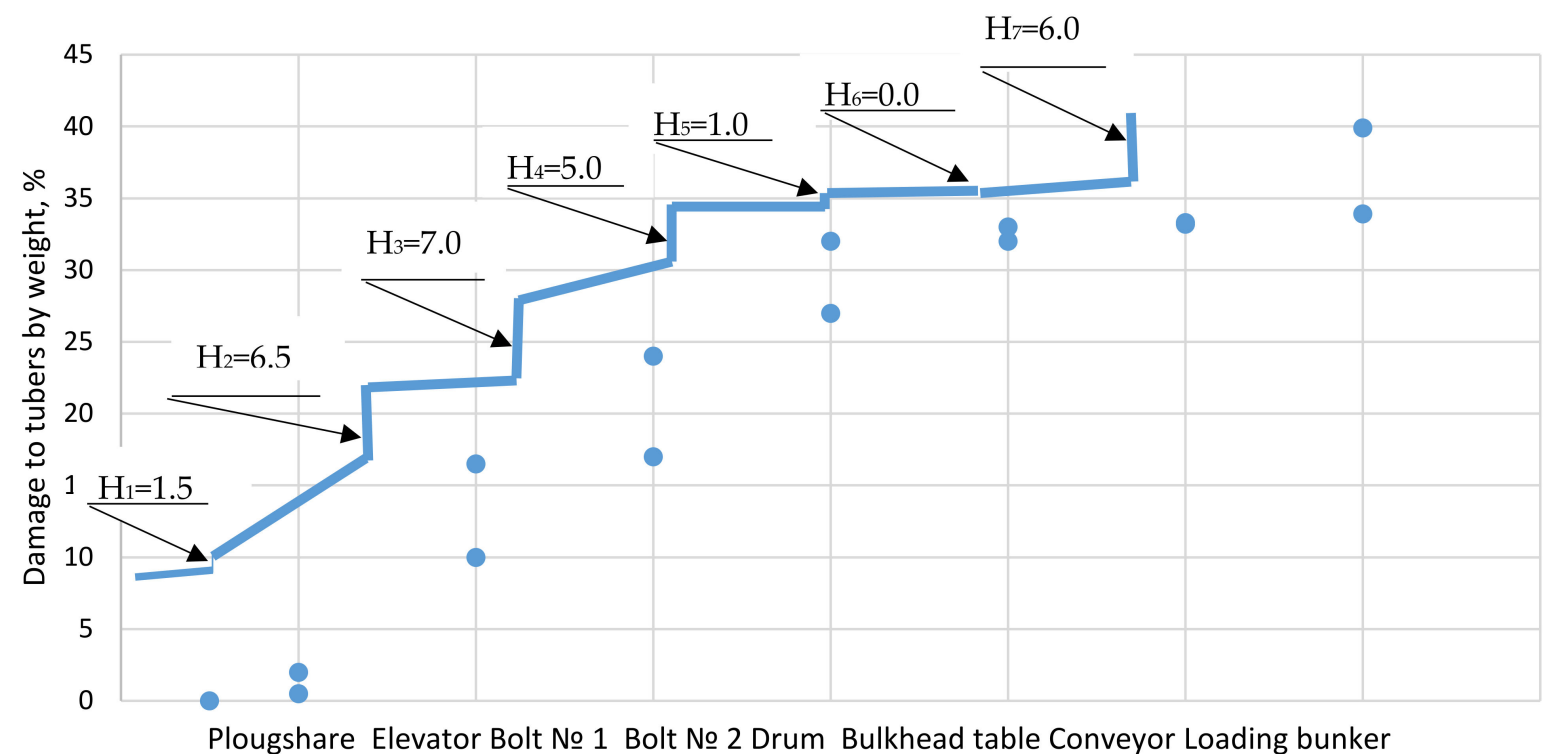

Figure 5. Damage to potato tubers on the working bodies of the combine. 


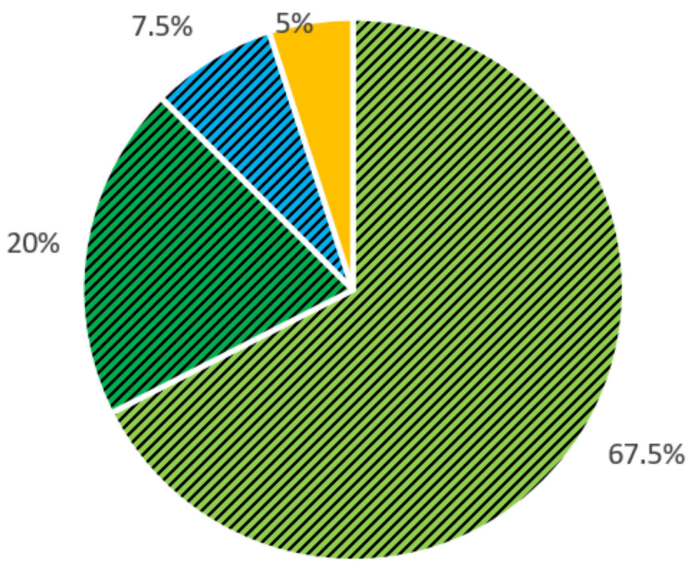

: On the drops

- At the main elevator

* On the screens of the roar

- On other working bodies

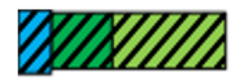

\section{on drops and separating working bodies (95\%)}

Figure 6. Specific gravity of damage to potato tubers on drops and separating working bodies as a percentage of the total amount of damage by weight.

The diagram shows that the transition of potato heap from a work element to another (drops), accounts for $67.5 \%$ of the total number of damaged tubers, while drops and separating work elements together account for $95 \%$ of tuber damage.

The range of existing methods for the evaluation of small batches of tubers mainly focuses on the discovery of individual factors. In addition, the response of varieties and hybrids is different depending on the testing method of mechanical action resistance used. This means that tests should be carried out using the methods that would closely simulate the conditions occurring during a standard harvester-based pickup.

For this reason, procedures and technical means are required that would make it possible to evaluate seed stock in terms of resistance to mechanical damage on a limited number of tubers available.

Therefore, the objective of this study is the quantitative and structural evaluation of damage to potato varieties and hybrids resulting from the device simulating the operation of harvester separating elements depending on the machine type and harvesting conditions.

\section{Material and Methods}

The block diagram of the research methodology is shown in Figure 7.

In order to perform a detectable force action on potato tubers to simulate the action of the harvester's operating elements, a device was developed; its structural and operational diagram and general view are shown in Figures 8 and 9, respectively.

The device is comprised of the drum with rubber-coated rods 1, blade 2 and the hatch for loading and unloading batches of tested tubers beneath the blade. Inside the drum, above its axis, pin hummock 3 is located, which allows the researchers to adjust the angle of inclination. Along the butt ends of the drum, fixed walls are installed that prevent tubers from rolling out of the drum and imitate side walls of elevator and side walls of other elements of potato harvesters.

The tuber damage testing device operates as follows.

A batch of tested potato tubers is placed into drum 1 through the hatch. Due to the clockwise rotation of the drum, blade 2 picks up the tubers and lifts them to a preset height, which may be adjusted by changing the inclination angle of the blade. During subsequent rotation of the drum, the tubers fall onto the pin hummock 3 . This simulates falls and movement of tubers along various conveyors of a harvester [18-20]. 


\section{The current state of the issue of potato harvesting}

1.1 Analysis of technologies and technical means for harvesting potato

1.2 Determination of factors influencing the technological process of onion harvesting, identification of design and technological parameters of technical means

\section{Theoretical analysis and justification of the parameters of technical means for harvesting potate}

2.1 Theoretical Substantiation of Design and Technological Parameters of Technical Means for potate harvesting:

calculation of parameters of technical means for harvesting potate;

obtaining theoretical dependencies to substantiate the design and technological parameters of technical means for harvesting potate

2.2 Study of the technological process of operation of technical means of potate harvesting, determination of initial parameters and evaluation criteria

Objective Function

Compliance Assessment

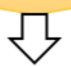

\section{Experimental studies of technical means for harvesting onions}

3.1 Development of a methodology for conducting experimental studies

3.2 Conducting laboratory studies to identify the intervals and levels of variation of independent factors and the nature of the change in the evaluation criteria for the operation of technical means for harvesting potate

3.3 Obtaining regression models and substantiating the optimal values of technological parameters of technical means for harvesting potate

3.4 Conducting production research to determine the optimal technological parameters of technical means for harvesting potate

No

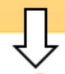

Objective Function

Compliance Assessment

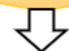

Yes

5 Development of recommendations for the introduction of potate harvesting machines equipped with the developed technical means

Figure 7. Structural scheme of research.

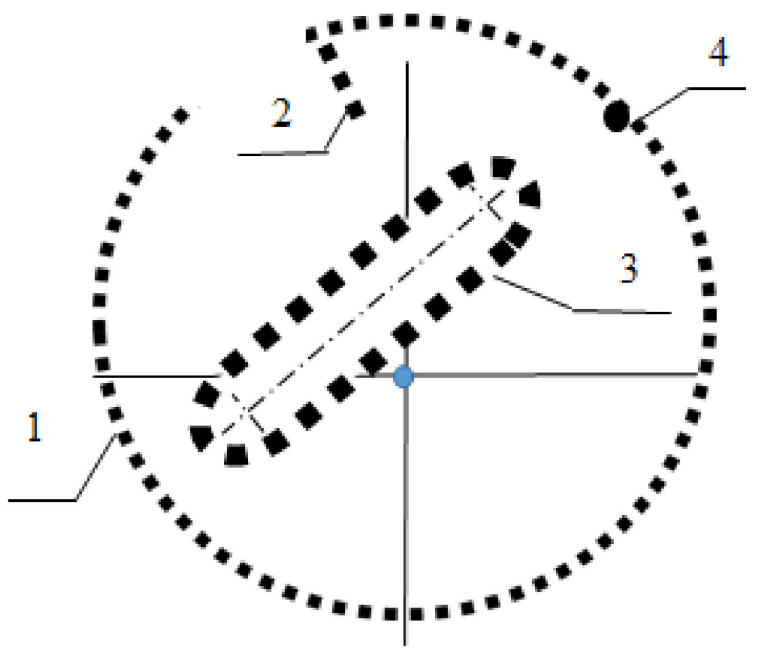

Figure 8. Structural and process diagram of the device for evaluation of suitability of potato varieties and hybrids for mechanized harvesting.:1—rod drum; 2-blade; 3 -pin hummock; 4-agitator. 



Figure 9. General view of the device for evaluation of suitability of potato varieties and hybrids for mechanized harvesting: 1—support platform; 2-control cabinet; 3-drum; 4-data logger; 5-pin hummock.

From the pin hummock 3, tubers roll down to rubber-coated rods of the drum (this simulates another drop) and continue to travel until they return to blade 2 . This imitates the operation of the elevator of a potato harvester.

While rolling inside the drum, tubers hit rod 4, which simulates the elevator's agitator. Stationary side walls at the ends of the drum prevent tubers from rolling out of the drum and from the pin hummock, thus simulating the side walls of the elevator and the adjacent conveyors of a potato harvester [20].

After a preset number of cycles, the drum's movement is reversed, and the tubers exit via the hatch into the collecting container while the drum stops automatically.

The number of cycles is determined based on the number of falls and the distance traveled by potato tubers along the potato harvester's elevator.

The number of cycles for each type of potato harvester is determined using the calibration method during actual potato harvesting in the field.

The drop height of the simulator is limited by structural dimensions of the drum, and should conform with drops of potato harvesters. A more precise adjustment of the damage simulator to simulate a specific harvester is achieved by changing the angle of inclination of blade 2 and changing the location of pin hummock 3 of the simulator.

It was determined that this relative share of individual damage groups accounts for about $70 \%$ of internal damage (darkening of tissue) which occurs under impact stress at separating work elements and at drops between them.

The procedure to determine the amount describing the resistance of a tuber jacket and its tissue to mechanical action involves the determination of the intensity of effort needed to introduce a blunt instrument into the body of a tuber with jacket.

In order to determine the location and record the amount of the maximum force action of the test device for evaluation of the suitability of potato varieties and hybrids for mechanized harvesting, as well as in order to develop recommendations of future design and process parameters of potato sorting machines, experimental studies were carried out with the use of the Electronic Potato (Tuber Log) (Martin Lishman) software at FRAIC VIM facilities.

The Electronic Potato (Tuber Log) (Martin Lishman) software tool (Figure 10) comprises: data logger 1 having the shape, size and density similar to those of a standard potato tuber; personal 2 or tablet computer 3 with the installed software suite for the processing of recorded data of root crop damage and its subsequent analysis; as well as auxiliary devices 4 . 


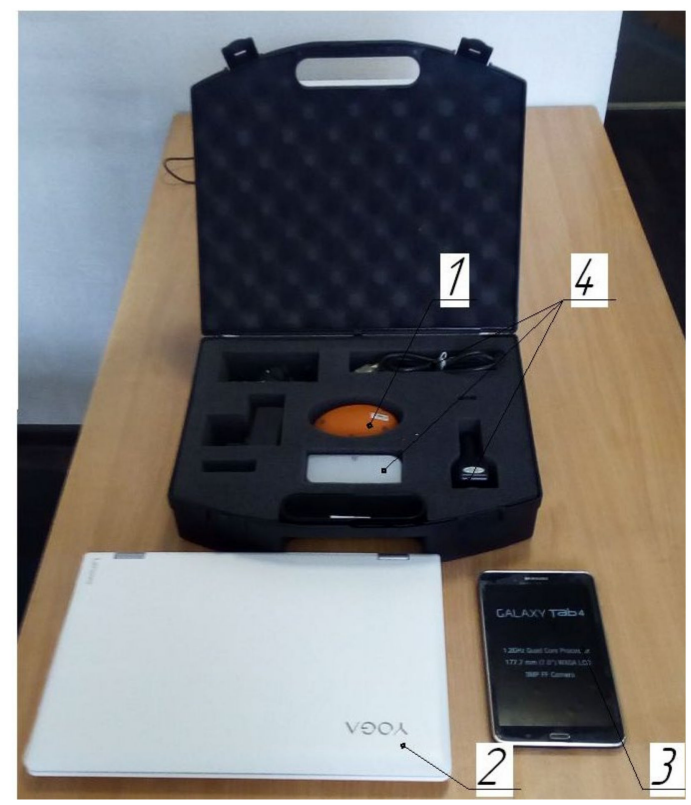

Figure 10. General view of Electronic Potato (Tuber Log) software tool: 1—data logger; 2-personal computer; 3-tablet computer; 4-auxiliary equipment.

The experimental studies of force action on potato tubers were carried out using the test device for evaluation of suitability of potato varieties and hybrids for mechanized harvesting. The design and theory of operation of the test device were developed at FSBSI FRAIC VIM (Figure 11).
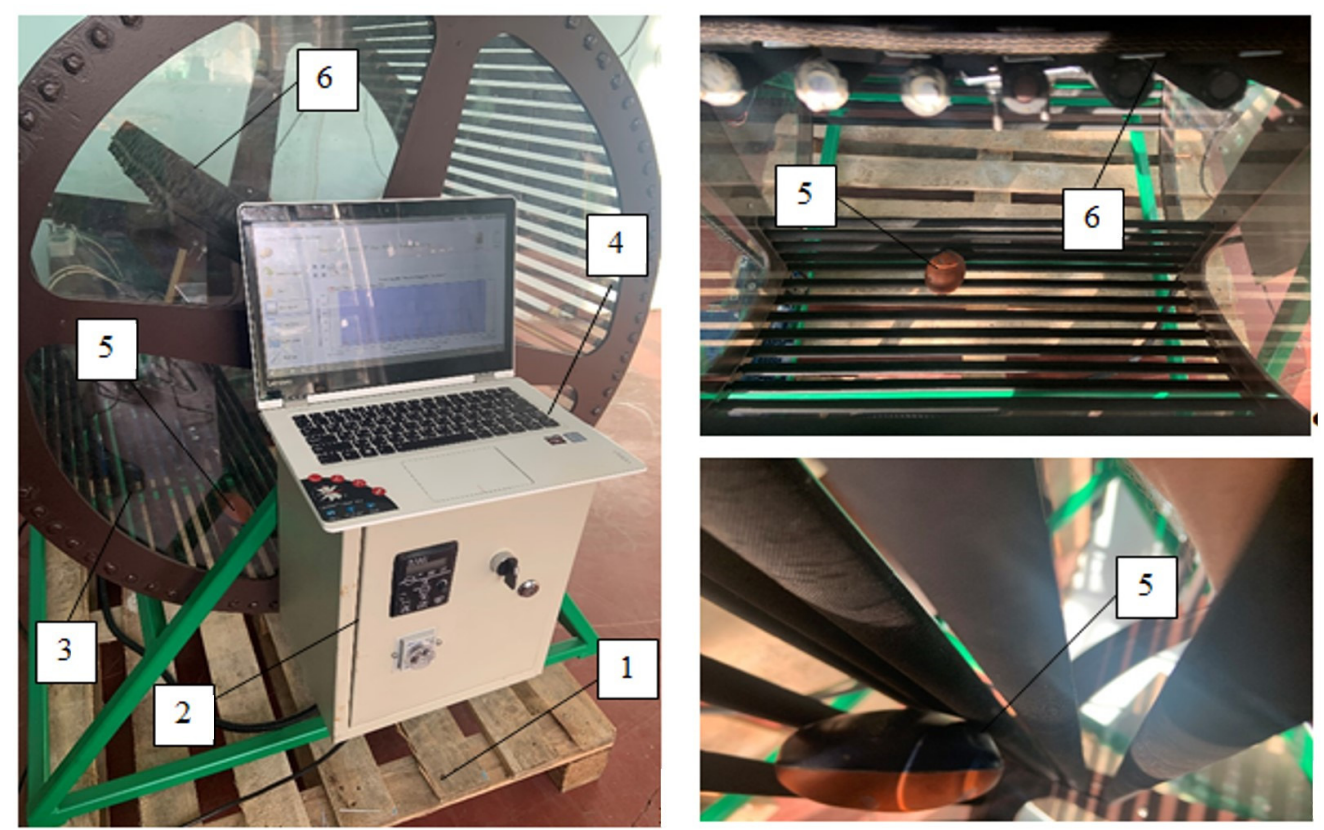

Figure 11. General view of the laboratory setup for studies of force action of the test device for evaluation of suitability of potato varieties and hybrids for mechanized harvesting: 1-support platform; 2-control cabinet; 3-drum; 4-personal computer; 5-data logger; 6-pin hummock.

The Electronic Potato enables the researchers to register the amount of imparted acceleration, as well as the impact impulse imparted during interaction with work elements of the laboratory setup with the aim of determining the force action of operating elements of the developed device:

$$
\mathrm{F}=\mathrm{m} \times \mathrm{g},
$$


where $\mathrm{m}$ is the weight of the Electronic Tuber in $\mathrm{kg}(\mathrm{m}=0.2 \mathrm{~kg})$; $\mathrm{g}$ is the free-falling acceleration in $\mathrm{m} / \mathrm{s}^{2}\left(\mathrm{~g}=9.8 \mathrm{~m} / \mathrm{s}^{2}\right)$.

Studies to determine locations of damage using the test device were conducted at various values of rate of rotation of the separating drum and travel speed of the pin hammock $n_{\mathrm{EL}} \mathrm{V}_{\mathrm{EL}}$. The research procedure was as follows. Optimal values of the rate of rotation of the separating drum and travel speed of the pin hammock were set as $n_{\mathrm{EL}} V_{\mathrm{EL}}$.

Following that, the drive of the drum of the test device for evaluation of suitability for mechanized harvesting was engaged. After stable movement of work surfaces of the test device for evaluation of suitability for mechanized harvesting 1 had been achieved, Electronic Potato 2 was introduced.

After Electronic Potato 3 had passed the separating surface, the video recorder and the control cabinet 2 was switched off, studied factors were adjusted and the experiment was repeated in accordance with the selected experiment plan. The studied parameter-the impact action on the potato tuber-was measured three times, following which the ordered series was evaluated using mean values of weight measurements.

Conventional concepts and elements of variation statistics characterizing the ordered series, mean variation $\bar{X}$, mean square deviation $\sigma$ and variation coefficient $v$ were used in the evaluation. Each of the main elements were determined using the established variation statistics formulas. This made it possible to determine the accuracy of experimental data and set tolerable limits within which they would be sufficiently reliable. In order to determine the number of variation intervals $(\mathrm{K})$ of the values of force action on the potato tuber, the following empirical relationship was used:

$$
\mathrm{K}=\sqrt{ } \mathrm{n},
$$

where $\mathrm{n}$ is the number of studied bulbs, pcs. In our case, this resulted in: $\mathrm{K}=\sqrt{ } 100=10$.

The sample range is:

$$
\mathrm{R}=\mathrm{xmax}-\mathrm{xmin},
$$

where xmax and xmin are the maximum and the minimum values of the studied characteristic, respectively.

The interval width of the studied characteristic is:

$$
\mathrm{D}=\mathrm{R} / \mathrm{K} \text {. }
$$

Study results were recorded in the observation log.

When studying the effect of process parameters of separating surface rollers on the degree of the sorting material force action, experiments were carried out four times.

A visual representation of the results of studies of force action of the separating surface represented by rod drum simulating the operation of rod elevator of a potato harvester is shown in Figure 10.

Using the shown dependence diagrams, it is possible to determine the location of the greatest force action on the separated products, which makes it possible to adjust design parameters of separation surfaces and optimize mode and process parameters. In order to do this, after the determination of the respective section based on the length of the separating surface, a right line parallel to the $y$-axis needs to be drawn until it intersects the graph.

\section{Results and Discussion}

An analysis of the dependence diagrams (Figure 12) developed as a result of the experimental studies of the test device for evaluating the suitability of potato varieties and hybrids for mechanized harvesting makes it possible to conclude that the maximum force action $(\mathrm{F}=20.3 \mathrm{~N})$ on potato tubers occurs when the tuber is transferred from the pin hummock onto the work surface of the separating drum within the time interval of 9 to $11 \mathrm{~s}$. 

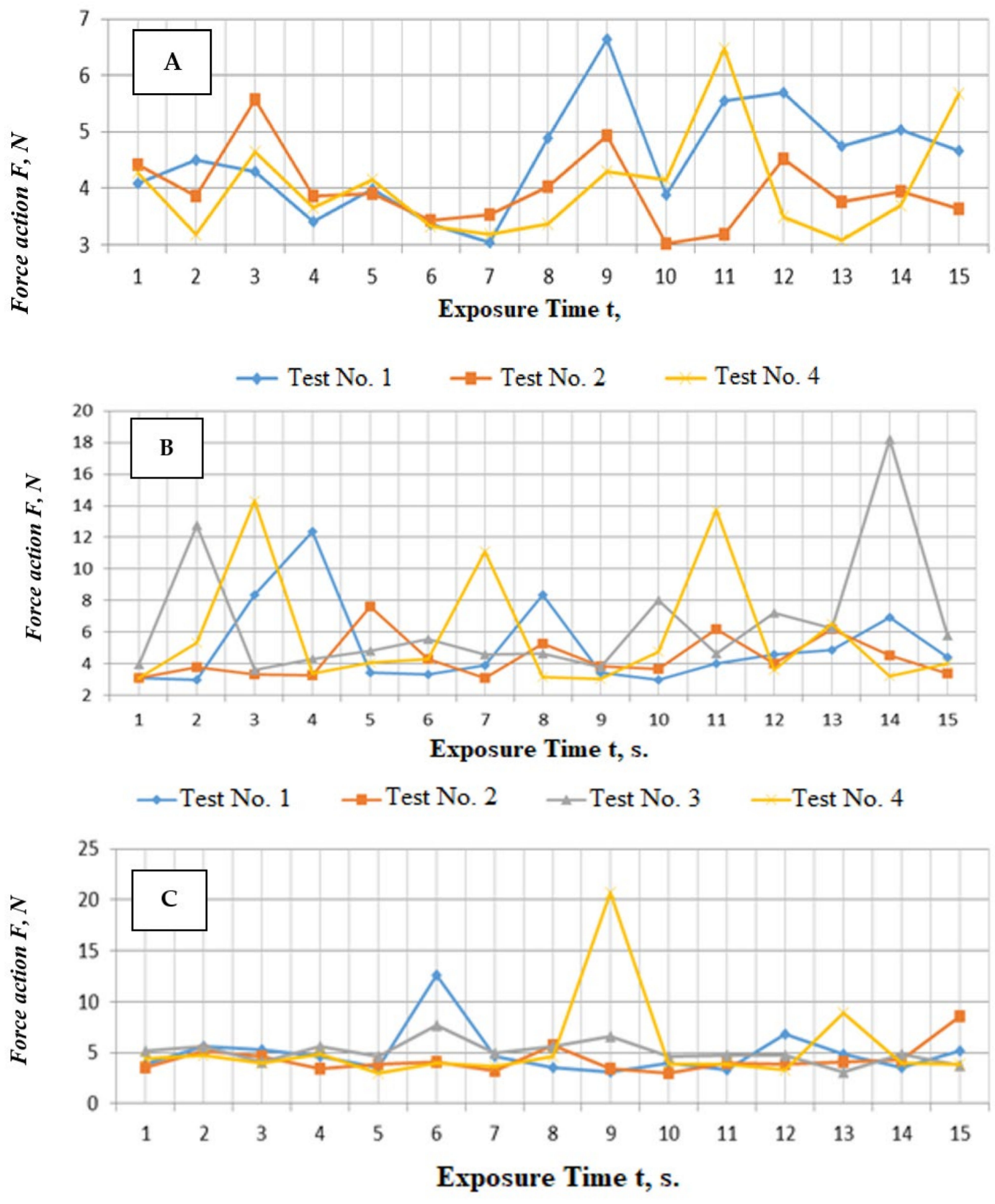

$\rightarrow$ Test No. $1 \rightarrow$-Test No. $2 \rightarrow$ Test No. $3 \rightarrow$ Test No. 4

Figure 12. Force action of the work surface of the pin hummock on potato tuber: (A) -annular travel speed of roller separating surface $V_{E L}=3.6 \mathrm{~km} / \mathrm{h}$; (B)-annular travel speed of roller separating surface $V_{E L}=5.0 \mathrm{~km} / \mathrm{h} ;(\mathbf{C})$-annular travel speed of roller separating surface $V_{E L}=6.4 \mathrm{~km} / \mathrm{h}$.

This circumstance should be explained by the fact that in the course of the data logger, travel along the separating surfaces of the test device for evaluating the suitability of potato varieties and hybrids for mechanized harvesting, irrelevant of the travel speed of the pun hummock, the belt is lifted along the vertical plane due to the action of separation intensifier. 
The intensifier is used in the design of the machine in order to create additional torque for the purpose of orientating the tuber towards the slot and increase the time of the tubers' interaction with the separating surface.

The interpretation of the graphical dependencies presented in Figure 9 obtained during experimental studies confirms that the greatest force effects $(\mathrm{F}=18 \mathrm{~N})$ on potato tubers are observed in the time range of 10-11 s, as well as at $14 \mathrm{~s}$ of separation of the tuberous heap, which corresponds to the finding of tubers and the effect of the working elements of the harvester in real conditions during the transfer of the separated products from the bucket elevator to the hedgehog and on the bulkhead table, respectively.

In addition, an increase in the force effect during the separation of the tuberous heap is observed during the transition from the digging working body to the main elevator up to $14 \mathrm{~N}(\mathrm{t}=2 \mathrm{~s})$, as well as directly at the main elevator $(\mathrm{F}=14 \mathrm{~N}, \mathrm{t}=3 \mathrm{~s})$.

The above factors cause the vertical component of force action of the separation intensifier to increase between the operating components of the pin hummock and potato tubers, resulting in the increase in the force action on tubers and thus in increased damage.

Analyses of the results of the experimental studies of force action on a potato tuber by work elements of the test device for evaluating the suitability of potato varieties and hybrids for mechanized harvesting demonstrated that the measured value varies within a wide range, depending on the location of the tuber at the functional element (variation coefficient $v=26.9 \%$, mean square deviation $\sigma=5.52$ ).

A time interval of 8.5 to $9.5 \mathrm{~s}$ accounts for the highest force action (of up to $22 \mathrm{~N}$ ) on the potato tuber (Figure 6); here, the mean square deviation and the variation coefficient are $\sigma=5.7$ and $v=24.8 \%$, respectively.

As a result of the variance analysis of the two-factor experiment, the following main statistical characteristics of the experiment were obtained:

- $\quad$ Variance of the experimental error, $S_{y}^{2}=7$;

- $\quad$ Standard error $S_{b k}=1.16$;

- $\quad$ error variance, $S_{b k}^{2}=1.36$;

- $\quad$ Dispersion of reproducibility, $S_{\text {repr }}^{2}=16.33$;

- $\quad$ Dispersion of inadequacy, $S_{\text {inadeq }}^{2}=1.368$;

- $\quad$ Tabular value of the $\mathrm{t} \mathrm{T}$-criterion, $t_{\mathrm{T} 0.05}=4.02$;

- $\quad$ Value of the tabular $\mathrm{t}$-criterion, $t_{0.05}=3.66$;

- Tabular value of the Fisher criterion at 5\% significance level for the resulting equation, $F_{T}=5.32$;

- The calculated value of the Fisher criterion at the 5\% significance level for the resulting equation, $F=2.2$.

The research program of the device for evaluating the suitability of varieties for mechanized harvesting of potatoes included field tests of potato harvesters and tests of the developed device in order to determine the mechanical damage to potato tubers when harvested by different potato harvesters and the corresponding damage to tubers on a simulator.

Experimental studies to assess the force impact of working bodies on potato tubers were carried out on potato harvesters of the following brands: AVR-Spirit-6200 combine (Belgium), Dewulf RA-3060 combine (Holland) and Bolko combine (Poland).

The methodology for conducting experimental studies is as follows.

Before conducting experimental studies on the accounting plot, the physical and mechanical properties of the soil were determined: moisture and hardness, according to the method of STO AIST 8.7-2013 "Machines for harvesting vegetables and melons. Methods for assessing functional indicators".

The technological parameters of the potato harvester before the research were set to optimal operating modes, in which the depth $\mathrm{h} \_\mathrm{L}$ of digging share into the soil was set below the depth of potato tubers in the range of $0.12-0.18 \mathrm{~m}$, due to the planting depth of tubers. 
To carry out these studies, we set up a number of experiments when harvesting with potato harvesters: AVR-Spirit-6200 (Belgium), a Dewulf RA-3060 combine (Holland) and a Bolko combine (Poland), as well as during the operation of a tuber damage simulator, the technological schemes of which are presented in Figures 13-15.



Figure 13. Technological scheme of the AVR-Spirit-6200 combine: 1-frame; 2-vertical disks; 3-digging share; 4-support wheel; 5-main elevator; 6-shaker; 7-cascade elevator; 8-finger slide; 9-bucket elevator; 10 -bulkhead table; 11 -bunker.

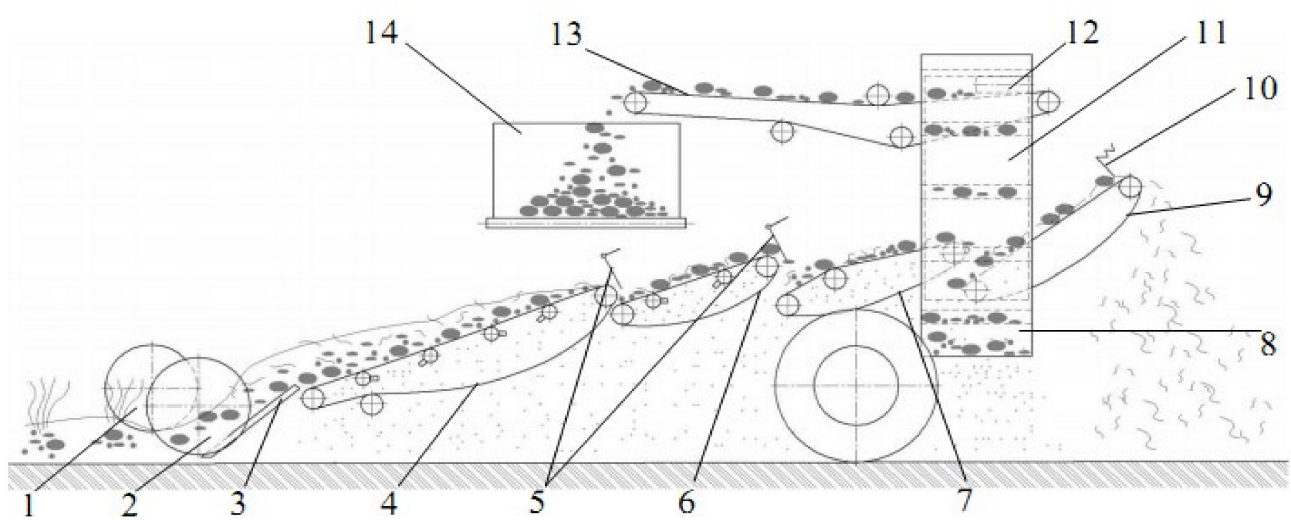

Figure 14. Technological scheme of the combine "Dewulf RA-3060": 1-rollers; 2-vertical disks; 3-plowshare; 4-main elevator; 5-defoliators; 6-cascade elevator; 7-additional elevator; 8-bucket elevator; 9-finger slide; 10-baffle element; 11-supporting tape; 12-shaft; 13-bulkhead table; 14-bunker.

The determination of the mechanical damage of tubers during the experiments was carried out from each repetition of clean tubers weighing more than $50 \mathrm{~g}$ for damage analysis. The mass of the average sample was $10 \mathrm{~kg}$. Four replicates were taken. During the analysis, the tubers were sorted into two groups: intact and damaged.

Samples were taken in triplicate, and the percentage of damaged tubers was determined with a confidence probability of 0.95 . The tuber tests on a simulator were carried out on the same day as experiments to determine damage when harvested by combine harvesters. 


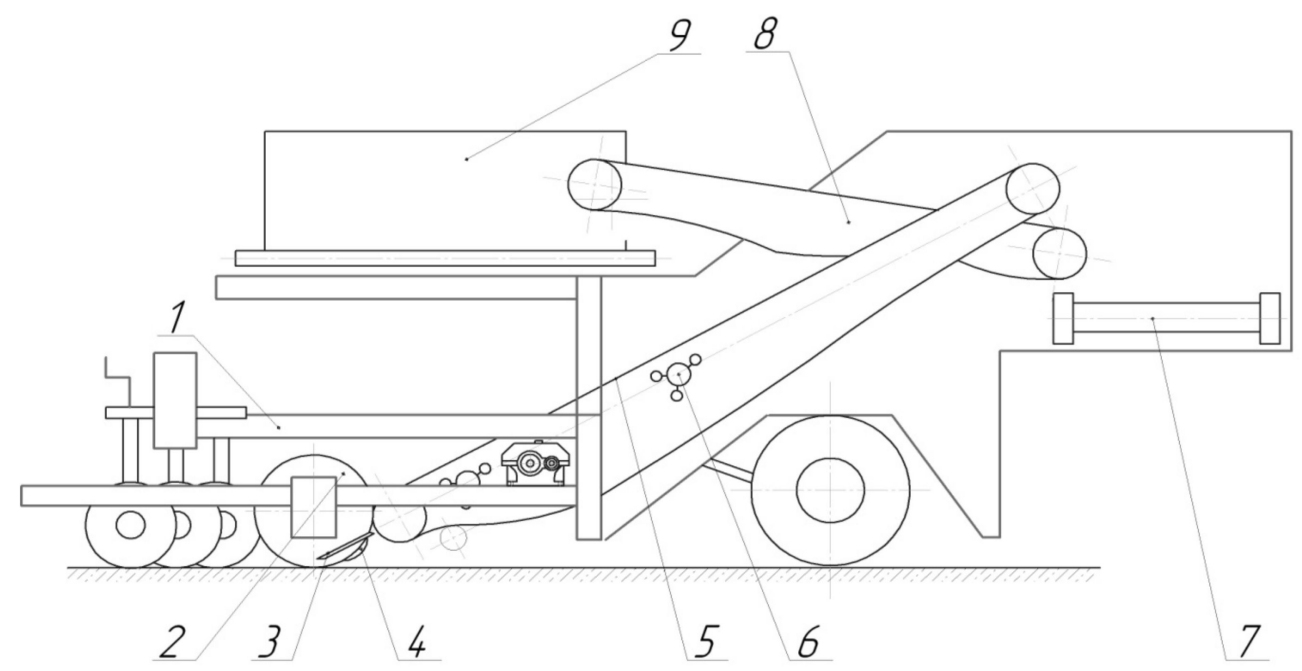

Figure 15. Structural and technological scheme of the combine "Bolko": 1-frame; 2-vertical disks; 3-digging share; 4-support wheel; 5-main elevator; 6-shaker; 7-transverse elevator; 8-bulkhead table; 9-bunker.

The results of the studies between indicators of resistance to mechanical damage during comparative tests of potato harvesters and the work of a specially designed tuber damage simulator showed that there is a correlation between the damage of tubers when using the damage simulator and when harvesting with combines.

Analyzing the graphical dependencies presented in Figure 14, we came to the conclusion that the minimum value of the level of damage in the considered section of the response surface with a factor is $7.34 \%$ and takes place at a combine operating speed of $1.875 \mathrm{~km} / \mathrm{h}$ and when harvesting with a combine.

The optimal values of the factors under consideration are within the operating speed of $1.64-2.11 \mathrm{~km} / \mathrm{h}$. Thus, the correlation coefficient for skin peeling is equal on average to 0923 and, according to the darkening of the pulp, 0.936 (Figure 16).

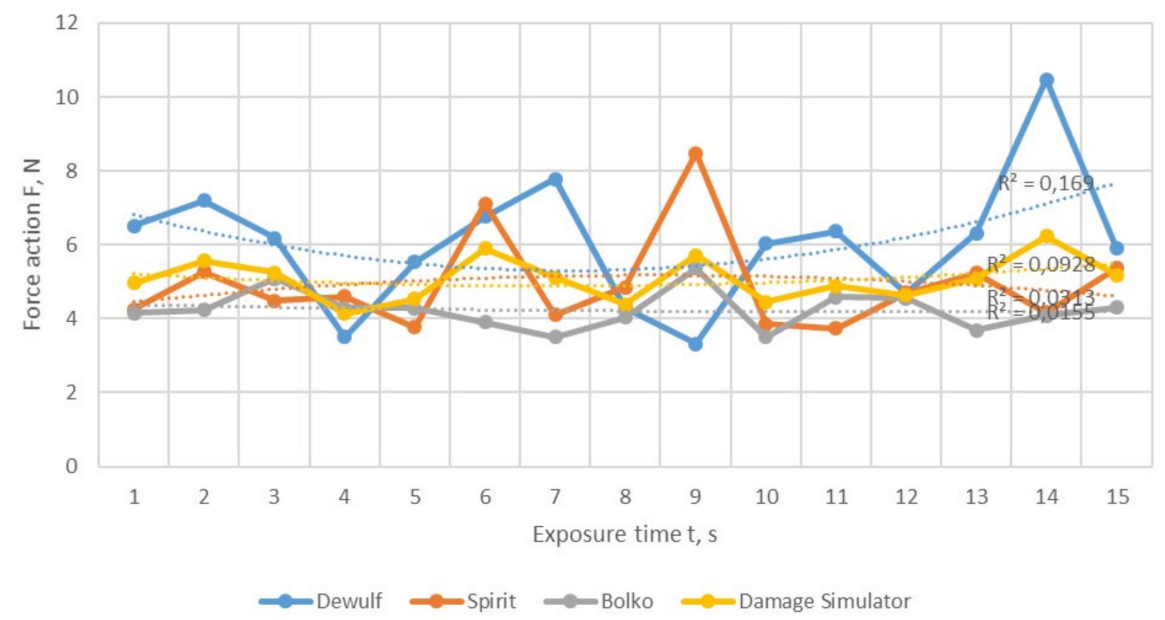

Figure 16. Comparison of force action of separating surfaces on a potato tuber within the test device for evaluation of suitability of potato varieties and hybrids for mechanized harvesting.

When analyzing the research results, it was found that the maximum correlation is observed between the indicators of mechanical damage to tubers during the operation of combines and on the simulator for the following types of damage: cracks more than $20 \mathrm{~mm}$ long and darkening of the pulp more than $5 \mathrm{~mm}$ deep. Thus, it can be concluded that the simulator simulates drops, that is, impacts of tubers on the bar surface (darkening of the pulp and cracks), as well as the effect of separating organs (peeling). 
To determine the law of distribution of experimental studies (force impact) of a device for assessing the suitability of varieties for mechanized harvesting of potato tubers, we construct a statistical series by arranging information about the force impact $(\mathrm{F}, \%)$ in ascending order (1):

$$
X=\left(\begin{array}{l}
X_{0}=1.0 \\
X_{1}=2.1 \\
X_{2}=3.2 \\
X_{3}=4.3 \\
X_{4}=5.4 \\
X_{5}=6.5 \\
X_{6}=7.6 \\
X_{7}=8.7 \\
X_{8}=9.8 \\
X_{9}=10.9 \\
X_{10}=11.0 \\
X_{11}=12.1 \\
X_{12}=13.2 \\
X_{13}=14.3 \\
X_{14}=15.4 \\
X_{15}=16.5 \\
X_{16}=17.6 \\
X_{17}=18.7 \\
X_{18}=19.8 \\
X_{19}=20.9 \\
X_{20}=20.2 \\
X_{21}=21.4 \\
X_{22}=22.3 \\
X_{23}=23.1 \\
X_{24}=24.4
\end{array}\right)
$$

The magnitude of the displacement of the distribution of force $(\mathrm{F}, \%)$ :

$$
X_{C M}=X_{0}-\frac{\left(X_{2}-X_{0}\right)}{2}=1.0-\frac{(3.2-1.0)}{2}=0.9 \%
$$

Average value of force impact $(v, \%)$ :

$$
\mathrm{X}_{\mathrm{CP}}=\frac{\sum_{\mathrm{j}=0}^{\mathrm{N}-1} \mathrm{X}_{\mathrm{J}}}{\mathrm{N}}=1.95 \%
$$

Standard deviation of force action (F, \%):

$$
\operatorname{Stdev}(x)=\sqrt{\frac{\sum_{\mathbf{j}=0}^{\mathrm{N}-1}\left(\mathbf{X}_{\mathrm{CP}}-\mathbf{X}_{\mathbf{j}}\right)^{2}}{\mathrm{~N}-1}}=\mathbf{0 . 2 9 3} .
$$

Force variation coefficient $(\mathrm{F}, \%)$ :

$$
v=\frac{\operatorname{Stdev}(x)}{X_{C P}-X_{C M}}=\frac{0.293}{1.95-0.9}=0.238 \text {. }
$$

Checking the information of the results of experimental studies using the Irwin criterion for the minimum value of the force impact $(v, \%)$ :

$$
\lambda_{0}=\frac{X_{1}-X_{0}}{\operatorname{Stdev}(x)}=\frac{1.1-1.0}{0.293}=0.395 .
$$


Irwin's criterion for the maximum value of the force impact (F, \%):

$$
\lambda_{N}=\frac{X_{N-1}-X_{N-2}}{\operatorname{Stdev}(x)}=\frac{2.9-2.7}{0.293}=0.791 .
$$

The critical value of the Irwin criterion for probability:

$$
\lambda_{\mathrm{KP}}=0.3832+\frac{2.38764}{\mathrm{~N}}=1.321 .
$$

If the calculated value of the Irwin criterion is greater than the critical value (the inequalities are not 1 , but zero), then the minimum and maximum points are outliers and should be removed from the original information. According to the coefficient of variation (v), we accept the distribution law of the force action: the law of normal distribution or the law of the Weibull distribution when the coefficient of variation is in the range of 0.3 to 0.7 .

The value of the interval (dX), as well as the vector of initial and final values $(\mathrm{X}(\mathrm{ni}))$ of the force impact $(\mathrm{F}, \%)$ for each interval (the final value of the interval is the initial value of the next interval):

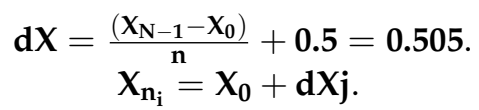

The frequency of hits in each interval $(\mathrm{m})$, as well as the vector of values for the midpoints (Xk) and ends (X(ci)) of the intervals:

$$
\begin{gathered}
\mathbf{m}=\operatorname{hist}\left(\mathbf{X}_{\mathbf{n}}, \mathbf{X}\right) . \\
\mathbf{X}_{\mathbf{k}}=\mathbf{X}_{\mathbf{n}}+\mathbf{d X} . \\
\mathbf{X}_{\mathrm{c}_{\mathrm{i}}}=\mathbf{X}_{\mathrm{n}_{\mathrm{i}}}+\frac{\mathbf{d X}}{2}
\end{gathered}
$$

Numeric values of parameters $(\mathrm{m}),(\mathrm{Xk})$ and $(\mathrm{X}(\mathrm{ci}))$ :

$$
\begin{aligned}
\mathbf{m} & =\left(\begin{array}{l}
2 \\
3 \\
5 \\
9 \\
7
\end{array}\right) \\
\mathbf{X}_{\mathbf{n}}= & \left(\begin{array}{l}
11.0 \\
11.2 \\
11.4 \\
11.6 \\
11.8 \\
11.9
\end{array}\right) \\
\mathbf{X}_{\mathbf{k}}= & \left(\begin{array}{l}
11.2 \\
11.4 \\
11.6 \\
11.8 \\
11.9 \\
12.1
\end{array}\right) \\
\mathbf{X}_{\mathrm{c}_{\mathrm{i}}}= & \left(\begin{array}{l}
11.3 \\
11.5 \\
11.7 \\
11.9 \\
12.1 \\
12.3
\end{array}\right)
\end{aligned}
$$


Differential function of the normal distribution law:

$$
\begin{aligned}
\mathbf{f}_{\mathrm{N}_{\mathrm{i}}}=\frac{\mathrm{dX}}{\sigma \cdot \sqrt{2 \pi}} \cdot \mathrm{e}^{\frac{-\left(\mathrm{X}_{\mathrm{C}_{\mathrm{i}}}-\mathrm{X}_{\mathrm{cp}}\right)^{2}}{2 \sigma^{2}}} . \\
\mathbf{f}_{\mathrm{N}}=\left(\begin{array}{c}
0.0334 \\
0.1303 \\
0.2344 \\
0.2433 \\
0.1467 \\
0.0438
\end{array}\right) .
\end{aligned}
$$

Before calculating the differential function of the Weibull law, we determine the parameters of this law. The Weibull law forms parameter $b$, which we obtain by approximating the statistical series $\mathrm{X}$ :

$$
\mathrm{b}=0.756482 \cdot \mathrm{V}^{-0.8781}=2.383 \text {. }
$$

We calculate the scale parameter a by first determining the coefficient $\mathrm{kb}$ :

$$
\begin{gathered}
\mathrm{k}_{\mathrm{b}}=0.75996-0.179954 \cdot \mathrm{V}+0.191137 \cdot \mathrm{V}^{2}=0.634 . \\
\mathrm{a}=\frac{\mathrm{X}_{\mathrm{CP}}-\mathrm{X}_{\mathrm{CM}}}{\mathrm{k}_{\mathrm{b}}}=\frac{1.95-0.9}{0.634}=1.65
\end{gathered}
$$

The differential function of the Weibull distribution law is:

$$
\begin{gathered}
\mathbf{f}_{\mathrm{W}_{\mathrm{i}}}=\frac{\mathrm{b} \cdot \mathrm{dX}}{\mathrm{a}} \cdot\left(\frac{\mathrm{X}_{\mathrm{c}_{\mathrm{i}}}-\mathrm{X}_{\mathrm{CM}}}{\mathrm{a}}\right)^{\mathbf{b}-1} \cdot \mathrm{e}^{\left[-\left(\mathrm{X}_{\mathrm{c}_{\mathrm{i}}}-\mathrm{X}_{\mathrm{CM}} / \mathbf{a}\right)^{\mathbf{b}}\right]} . \\
\mathbf{f}_{\mathrm{W}_{\mathrm{i}}}=\left(\begin{array}{c}
0.0398 \\
0.1578 \\
0.2385 \\
0.2231 \\
0.1353 \\
0.0464
\end{array}\right) .
\end{gathered}
$$

For a more accurate choice of the distribution law, we use the Pearson criterion $\chi^{2}$ (Figure 17).

$$
\begin{aligned}
& \chi_{\mathbf{N}}^{2}=\sum_{i=0}^{n-1} \frac{\left(\frac{\mathbf{m}_{\mathbf{i}}}{\mathbf{N}}-\mathbf{f}_{\mathrm{N}_{\mathbf{i}}}\right)^{2}}{\mathbf{f}_{\mathrm{N}_{\mathrm{i}}}}=\mathbf{0 . 1 1 5 0 2 .} \\
& \chi_{\mathrm{W}}^{2}=\sum_{\mathrm{i}=0}^{\mathrm{n}-1} \frac{\left(\frac{\mathrm{m}_{\mathrm{i}}}{\mathrm{N}}-\mathrm{f}_{\mathrm{W}_{\mathrm{i}}}\right)^{2}}{\mathrm{f}_{\mathrm{W}_{\mathrm{i}}}}=0.11286 .
\end{aligned}
$$

Required error significance level:

$$
\alpha=0.15 \text {. }
$$

Number of degrees of freedom:

$$
\xi=\operatorname{length}\left(X_{n}\right)-1=4 .
$$

The value of Pearson's critical criterion $\chi^{2}$ corresponding to the given value $\alpha$ :

$$
\chi^{2}=\text { qchisq }(\alpha, \xi)=2.638
$$

Probability of coincidence of experimental data with calculated ones:

$$
\begin{gathered}
\mathbf{P}_{\mathbf{N}}=1-\operatorname{pchisq}\left(\chi_{\mathbf{N}}^{2}, \xi\right)=1 \\
\mathbf{P}_{\mathbf{W}}=1-\operatorname{pchisq}\left(\chi_{W}^{2}, \xi\right)=0.977541
\end{gathered}
$$




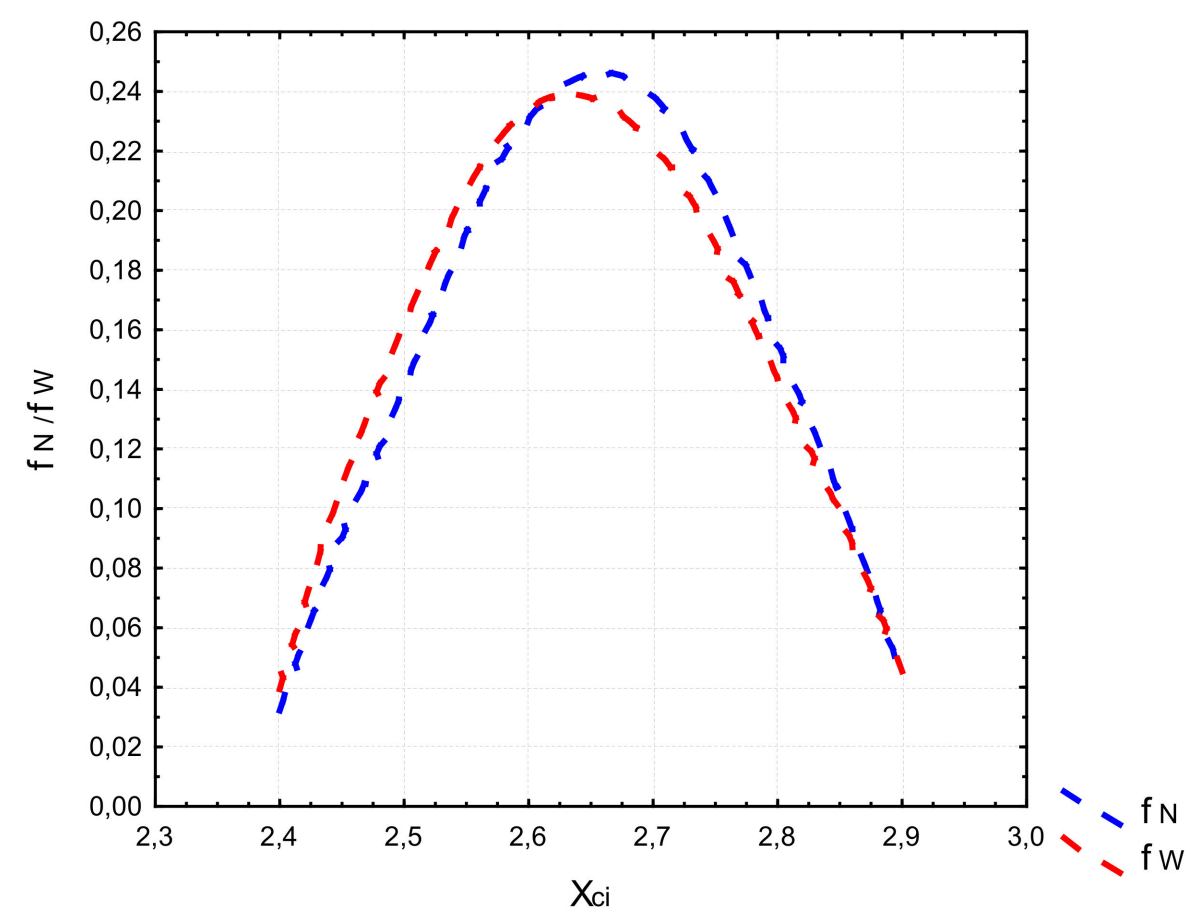

Figure 17. Differential functions of theoretical distribution laws: normal and Weibull.

The hypothesis of correspondence to the considered distribution law has the right to exist if the following inequality is satisfied:

$$
\chi_{\mathrm{N}}^{2}<\chi^{2}=1, \chi_{\mathrm{W}}^{2}<\chi^{2}=1 .
$$

The acceptable minimum probability $\left[\mathrm{P}_{\chi_{\min }^{2}}\right]$ of coincidence of the experimental data with the calculated ones according to the criterion $\chi^{2}$ is $10 \%$. Since, in our case, the probability is $\mathrm{P}_{\mathrm{N}}>\mathrm{P}_{\mathrm{W}}$ и $\mathrm{P}_{\mathrm{N}}>\left[\mathrm{P}_{\chi_{\min }^{2}}\right]=0.1$, then the law of normal distribution of force on the device for assessing the suitability of varieties for mechanized harvesting on potato tubers can be taken as the main distribution law. Let us define the boundaries of the confidence interval $(\mathrm{L}, \mathrm{U})$, within which lies with a confidence probability $(100 \times(1-\alpha)=95 \%)$ the variance of a normal random variable, based on the sample size $\mathrm{N}=20$ (Figure 18).

$$
\begin{gathered}
\chi_{0}^{2}=\operatorname{qchisq}\left(\frac{\alpha}{2}, \mathbf{N}-1\right)=24.387 \\
\chi_{1}^{2}=\operatorname{qchisq}\left(1-\frac{\alpha}{2}, N-1\right)=56.483 \\
\mathrm{~L}=\frac{(\mathrm{N}-1) \cdot \operatorname{Stdev}(\mathrm{x})}{\chi_{1}^{2}}=1.27 \\
\mathrm{U}=\frac{(\mathrm{N}-1) \cdot \operatorname{Stdev}(\mathrm{x})}{\chi_{0}^{2}}=2.987
\end{gathered}
$$

Mathematical expectation $\mathrm{M}(\mathrm{X})$ of the normal law of force distribution on the device for assessing the suitability of varieties for mechanized harvesting on potato tubers (Table 1):

$$
\mathbf{M}(\mathbf{X})=\mathbf{0 . 3}
$$




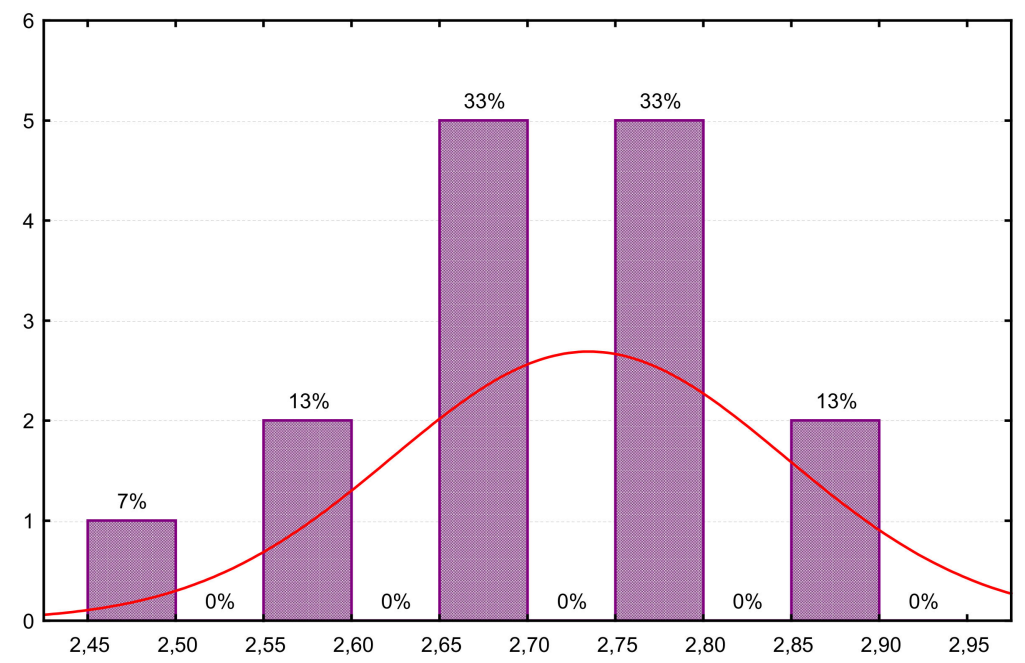

Figure 18. Histogram of experimental data sample values.

Table 1. Calculation of statistics criterion-distribution of a random variable over intervals.

\begin{tabular}{cccccccccc}
\hline & Observed & Cumulative & Percent & Cumul.\% & Expected & Cumulative & Percent & Cumul.\% & Observed- \\
\hline$<=\mathbf{2 . 5 0 0 0 0}$ & 0 & 0 & 0.00000 & 0.0000 & 0.269947 & 0.26995 & 1.79965 & 1.7996 & -0.26995 \\
$\mathbf{2 . 5 5}$ & 0.5 & 1 & 6.66667 & 6.6667 & 0.475739 & 0.74569 & 3.1716 & 4.9712 & 0.52426 \\
$\mathbf{2 . 6}$ & 1 & 3 & 13.33333 & 20.0000 & 0.985346 & 1.73103 & 6.56897 & 11.5402 & 1.01465 \\
$\mathbf{2 . 6 5}$ & 1.5 & 3 & 0.00000 & 20.0000 & 1.673209 & 3.40424 & 11.15473 & 22.6949 & -1.67321 \\
$\mathbf{2 . 7}$ & 2.5 & 8 & 33.33333 & 53.3333 & 2.329534 & 5.73378 & 15.53023 & 38.2252 & 2.67047 \\
$\mathbf{2 . 7 5}$ & 2.5 & 8 & 0.00000 & 53.3333 & 2.659225 & 8.39300 & 17.72817 & 55.9533 & -2.65923 \\
$\mathbf{2 . 8}$ & 2.5 & 13 & 33.33333 & 86.6667 & 2.488927 & 10.88193 & 16.59285 & 72.5462 & 2.51107 \\
$\mathbf{2 . 8 5}$ & 2 & 13 & 0.00000 & 86.6667 & 1.910022 & 12.79195 & 12.73348 & 85.2797 & -1.91002 \\
$\mathbf{2 . 9}$ & 1 & 15 & 13.33333 & 100.0000 & 1.201782 & 13.99373 & 8.01188 & 93.2915 & 0.79822 \\
<Infinity & 1 & 15 & 0.00000 & 100.000 & 1.006269 & 15.00000 & 6.70846 & 100.0000 & -1.00627 \\
\hline
\end{tabular}

Student's distribution quantile:

$$
\mathrm{T}=\mathrm{qt}\left(1-\frac{\alpha}{2}, \mathrm{v}\right)=2.012
$$

This is confirmed graphically by the observed and expected frequencies by constructing a scatter plot (Figure 19).

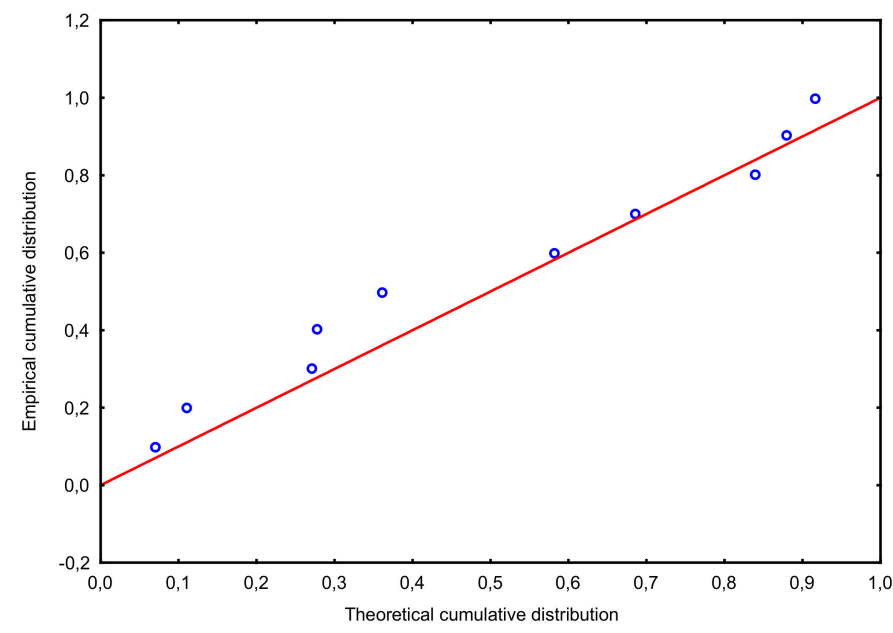

Figure 19. Histogram of experimental data sample values. 


\section{Conclusions}

The least harmful force action of the separator's work elements on the data logger was registered at the roller belt's annular speed $\mathrm{V}_{\mathrm{EL}}=$ of $1.4 \mathrm{~m} / \mathrm{s}$. In this case, the minimum force action on the separated products within the range of $3 \mathrm{~N}$ to $6.5 \mathrm{~N}$ was registered throughout the separation process. This accounts for 28 to $31 \%$ of the maximum force action of harvester work elements at travel speeds between 1.8 and $2.2 \mathrm{~m} / \mathrm{s}$.

The analysis of the experimental data presented in Figure 19 makes it possible to conclude that during the process of separation, tubers located at the work surfaces of the test device for evaluating the suitability of potato varieties and hybrids for mechanized harvesting interact both with active work elements and with other tubers.

The tubers fall onto the separation belt rollers when passing the shaking section and when passing from one roller to another. This is shown in the above dependence diagrams.

At drops between rollers, the tubers fall from the height of no more than $0.1 \mathrm{~mm}$, which corresponds to the collision velocity of $1.9 \mathrm{~m} / \mathrm{s}$ and conforms with the acceptable collision velocity of tubers $(2.2 \mathrm{~m} / \mathrm{s})$.

With the vertical component of the separating belt speed of $0.7 \mathrm{~m} / \mathrm{s}$ and higher, the speed of impact of the tubers thrown up by the separating surface of the drum following the action of the agitator exceeds $2.6 \mathrm{~m} / \mathrm{s}$, which is higher than the acceptable speed of impact of tubers with machine work elements. As the result, the tubers are damaged in this location.

Mechanical damage is a serious problem everywhere in the mechanized growing of seed and table potatoes and has been widely studied. Several investigators have shown that varieties vary considerably in resistance to mechanical injury [19]. In 1968, work dealing with the injury resistance of varieties commonly grown in Finland was started. This paper is the first report on that study.

The results of determining the mechanical properties of potatoes under quasi-static loading with the determination of parameters such as the vertical stress, modulus of elasticity, strain energy and strain force are known. These properties are considered basic information necessary in the design of machinery and equipment used during harvesting and post-harvest operations of potatoes to reduce costs.

Information about the mechanical properties of potatoes was obtained on a universal testing machine (MRI-5; Santum, Germany), with a single-axis compression test, to construct a deformation diagram with the tuber fixed between two parallel plates. In addition, in order to minimize mechanical damage and to reduce losses, the pressure forces that arose during the transfer and packaging of potatoes must be reduced to the minimum possible norm (below $8.8 \mathrm{~N}$ ).

Part of the losses of the agriculture products are related to the incorrect packaging method and inadequate transportation facilities. The packaging should be provided with the transportation and marketing needs in terms of the mass, dimension and shape of agriculture products, so this requires knowing the physical and mechanical properties. The information obtained in this research can be used in this regard. The true density of the potato was $1.05 \mathrm{~g} \cdot \mathrm{mm}^{-3}$, and this property can be used in designing the transfer, displacement and sorting systems. In a similar study, Celik et al. [18], Goyal [19] and Jahanbakhshi et al. [21,22] discussed and stressed upon the importance of these properties in determining the size of the machines, particularly that of the separation, transfer and sorting equipment [23-26].

The research results of D.P. Blight and A. J. Hamilton [27] indicate that the susceptibility of potato tubers to mechanical damage, as measured by the criterion of skin hardness, determined by a penetrometer, is not a satisfactory alternative to the damage index for determining the ratio of susceptibility to mechanical damage of tubers of different varieties. Many exceptions to the general trend of an inverse correlation between skin hardness and damage within have not been observed. The ratio of surface hardness to hardness at a depth of $2 \mathrm{~mm}$ provides only a very rough guide to cultivar susceptibility to damage, and therefore, this method of assessing damage to potato tubers is unsatisfactory. 
The authors V. Mayer, D. Vejchar, L. Pastorková [23] have tested a method for assessing the resistance of potato tubers to mechanical stress in two dimensions. In the first, four different varieties were compared under the same degree of mechanical stress, and in the second, the same potato variety was compared in different degrees of mechanical stress at a given constant temperature.

In the first measurement, samples of four varieties of potatoes were loaded with vibrations of a given frequency at a given lift on a test bench. This made it possible to compare the degree of internal damage, i.e., changes in the color of potatoes (darkening, blackening, graying) on the cut of the tuber, after the storage of samples of different varieties of potatoes for $48 \mathrm{~h}$ at the same temperature and humidity.

This method does not fully allow for an objective assessment of the resistance of potato tubers to mechanical harvesting in view of the possibility of simulating the mechanical load of the working heads of harvesters.

However, these methods cannot be used directly at the initial stages of breeding new varieties, it is possible only at the last stage of the breeding process-before the transfer of the variety to state tests. Hence, there was a need to develop a methodology and technical means to simulate the process of mechanical action on the tuber as much as possible, starting from the very initial stages of the breeding process with a small amount of the studied material.

\section{Managerial Implications}

The modern model of a potato variety includes more than 50 parameters for its assessment, the main of which are yield, resistance to diseases and pests, including mechanical damage. The resistance of the variety to mechanical damage is more important than other factors. This is due to the fact that bacteria and fungi gain more free access to the tissues of tubers that have received mechanical damage. The increasing mechanical load on the tubers, starting from planting and ending with the laying of new crop tubers for storage, determines the need for breeding for increased potato resistance to shock loads.

The assessment of the resistance of tubers to mechanical damage is best done when harvesting using industrial harvesters. However, this method cannot be used directly at the initial stages of breeding new varieties; it is possible only at the last stage of the breeding process-before the transfer of the variety to state trials. Hence, it became necessary to develop a methodology and technical means that would make it possible to simulate as much as possible the process of mechanical action on a tuber starting from the very initial stages of the selection process with a small amount of test material.

One of the most important requirements for modern potato varieties is their suitability for mechanized harvesting. Breeders are constantly working to create varieties with such properties. Ultimately, this makes it possible to achieve savings in material resources and labor costs, and to accelerate the obtaining of an objective assessment of the hybrid in the breeding process.

Author Contributions: Conceptualization, A.D. and A.A.; methodology, A.S. and M.G.; software, N.S. and A.P.; validation, A.A.; investigation, V.Z.; resources, M.G.; writing—original draft preparation, N.S.; writing—review and editing, S.P.; project administration, A.A.; funding acquisition, A.D. All authors have read and agreed to the published version of the manuscript.

Funding: This work was supported by a grant of the Ministry of Science and Higher Education of the Russian Federation for large scientific projects in priority areas of scientific and technological development (grant number 075-15-2020-774).

Institutional Review Board Statement: Not applicable.

Informed Consent Statement: Not applicable. 
Data Availability Statement: The raw data supporting the conclusions of this article will be made available by the authors, without undue reservation.

Acknowledgments: The device developed in accordance with the proposed conceptual scheme, further calibrated to account for modern potato harvesters, made it possible to conduct targeted selection of varieties suitable for mechanized cultivation, as well as to assess the degree of resistance of potato varieties to mechanized harvesting at early stages of selective and seed production works. In mass production, this would enable researchers to determine the timescale of combine harvesting of potato in order to prevent substantial losses of tubers during storage.

Conflicts of Interest: The authors declare that they have no known competing financial interest or personal relationship that could have appeared to influence the work reported in this paper.

\section{References}

1. Parke, D. The resistance of potato mechanical damage caused by impact loading. J. Agric. Eng. Res. 1963, 8, $173-177$.

2. Mc Gechan, J.S. An investigation into the damage sustained by different varieties of potatoes. J. Agric. Eng. Res. 1980, 25, 345-353. [CrossRef]

3. Dwelle, R.B.; Stallknecht, G.F. Rates of intemal blackspot bruise development in potato tubers under conditions of elevated temperatures and gas pressures. Am. Potato J. 1976, 53, 235-245. [CrossRef]

4. Hudson, D.E.; On, P.H. Incidence of mechanical injury to potatoes during certain storage-related handling operations in the Red River Valley production area. Am. Potato J. 1977, 54, 11-21. [CrossRef]

5. Turczyn, M.T.; Grant, S.W.; Ashby, B.H.; Wheaton, R.W. Potato shatter bmising during laboratory handling and transport simulation. Trans. ASAE 1986, 19, 1171-1175. [CrossRef]

6. Haan, P.H. Dutch grading and packing systems. Agric. Eng. 1983, 38, 49-52.

7. Schwarz, W. Bedienungsanleitung zum Schwingkasten für Kartoffelbelastungsuntersuchungen. Bornimer Agrartechnische Berichte, Institut für Agrartechnik Bornim e.V. Potsdam-Bornim. 2001, 2, 39-47.

8. Lobachevsky, Y.P.; Emelyanov, P.A.; Aksenov, A.G.; Sibirev, A.V. Onion Production Machine Technology; Federal State Budgetary Scientific Institution Federal Scientific Agroengineering Center VIM: Moscow, Russia, 2016; p. 168.

9. Kurdyumov, V.I.; Zykin, E.S.; Eroshkin, S.A.; Khaibullina, L.N. Theoretical justification of the diameter of the flat disk of the work tool of inter-row cultivator. Her. NGIEU 2017, 1, 54-60.

10. Kurdyumov, V.I.; Zykin, E.S.; Lazutkina, S.A. Justification of the distance between flat disks of inter-row cultivator. Her. Ulyanovsk. State Agric. Acad. 2016, 3, 174-178.

11. Pasaman, B.; Zakharchuk, V. The determination of the parameters of a ploughshare-rotor potato digger. Econtechmod. Int. Q. J. 2012, 1, 43-47.

12. Sibirev, A.V.; Emelyanov, P.A.; Aksenov, A.G. Experimental laboratory studies of cylindrical soil impurity sifter during the separation process. Her. Ulyanovsk. State Agric. Acad. 2017, 2, 33-36.

13. Dai, F.; Guo, X.H.; Zhao, W.Y.; Xin, S.L.; Liu, X.L.; Wu, Z.W. Design and experiment of canvas belt combined operation machine for potato digging and plastic film collecting. Trans. CSAM 2018, 49, 104-113.

14. Li, S.T.; Chen, X.B.; Chen, W.; Zhu, S.P.; Li, Y.W.; Yang, L. Soil-cutting simulation and parameter optimization of handheld tiller's rotary blade by Smoothed Particle Hydrodynamics modeling and Taguchi method. J. Clean. Prod. 2018, 179, 55-61. [CrossRef]

15. Sun, D.X.; Zhang, A.M.; Gong, J.X. Design and experiment on 1SZL-250A type subsoiling rotary tillage fertilizer combined soil working machine. J. Chin. Agric. Mech. 2016, 37, 1-6.

16. Devsh, K.; Ashok, T. Performance evaluation of tractor drawn potato digger cum-elevator. Int. J. Agric. Sci. Res. 2017, 7, 433-448

17. Nappe Mordi, N. Al-Dosary. Potato harvester performance on tubers damage at the eastern of Saudi Arabia. CIGR J. 2016, $18,32-42$.

18. Massah, J.; Lotf, A.; Arabhosseini, A. Effect of Blade Angle and Speed of Onion Harvester on Mechanical Damage of Onion Bulbs. Agric. Mech. Asia Afr. Lat. Am. 2012, 43, 60-63.

19. Lü, J.Q.; Shang, Q.Q.; Yang, Y.; Li, Z.H.; Li, J.C.; Liu, Z.Y. Design optimization and experiment on potato haulm cutter. Trans. CSAM 2016, 47, 106-114.

20. Lü, J.Q.; Sun, H.; Dui, H.; Peng, M.M.; Yu, J.Y. Design and experiment on conveyor separation device of potato digger under heavy soil condition. Trans. CSAM 2017, 48, 146-155.

21. Koga, N.; Kajiyama, T.; Senda, K.; Iketani, S.; Tamiya, S.; Tsuda, S. Energy efficiency of potato production practices for bioethanol feedstock in northern Japan. Eur. J. Agron. 2013, 44, 1-8. [CrossRef]

22. Goyal, R.K.; Kingsly, A.R.P.; Kumar, P.; Walia, H. Physical and mechanical properties of aonla fruits. J. Food Eng. 2007, 82, 595-599. [CrossRef]

23. Zavodnov, V.S.; Kyzmin, A.V.; Kuzmin, B.O. The results of comparative tests of tuber damage simulator and potato harvesters. Work. Mosc. Inst. Agric. Eng. M 1989, 38, 27-41. 
24. Jahanbakhshi, A. Determination of some engineering properties of snake melon (Cucumis melo var. flexuosus) fruit. Agric. Eng. Int. CIGR J. 2018, 20, 171-176.

25. Jahanbakhshi, A.; Abbaspour-Gilandeh, Y.; Mesri Gundoshmian, T. Determination of physical and mechanical properties of carrot in order to reduce waste during harvesting and post-harvesting. Food Sci. Nutr. 2018, 6, 1898-1903. [CrossRef]

26. Blight, D.P.; Hamilton, A.I. Variental susieptiblity to damage in potatoes. Rot. Res. 1974, 17, 269-270.

27. Mayer, V.; Vejchar, D.; Pastorková, L. Měření odolnosti hlíz brambor proti mechanickému zatížení. Res. Agric. Eng. 2008, 54, 22-31. [CrossRef] 